\title{
An investigation into the relationship between paracycling athletes and their prosthetics technology: a proposed design framework
}

Objective: Product attachment has been stated as an emotional relationship an end-user may develop with a tangible product or artefact. The objective of this study is to investigate this relationship with athletes who possess limb absence and utilise assistive sports technology competitively.

Method: Five elite paracyclists were surveyed using a modified 31 question product attachment survey. The survey comprised the ability to capture both closed-ended and open-ended data. The survey design itself was derived from three previously validated product relationship questionnaires.

Results: Four elite athletes with limb absence did not provide any firm evidence or indication to support the concept of a non-physical relationship with their prosthetic device. However, some respondents had (or wished) to incorporate some form of aesthetic-based prosthetic personalisation or customisation, as long as this did not impact on the prostheses functional performance. Furthermore, a thematic analysis of the participant's responses yielded a four-point assistive technology design philosophy framework. The emerging thematic areas were 1) The identification of the factors that influence performance in the athletes chosen sport; 2) To consider an 'appearance follows performance' approach; 3) To conduct sports specific trials of the prosthetic limb; and 4) To identify any need for prostheses decorative personalisation.

Conclusions: The survey revealed some anecdotes of a sports technology to user relationship but this will require further exploration with different and larger sample populations. Use of the proposed four-point framework may help inform practitioners of what considerations could provide greater end-user satisfaction when designing and developing specialised prosthetic limbs for elite-level sport.

\section{Implications for rehabilitation}

- Whilst the formal characteristics of product attachment were not broadly identified in this study, some indications may give credence for prosthetists to 
consider an 'appearance follows performance' approach to sports prostheses design. This may improve end-user satisfaction with their assistive technology.

- The inclusion of prosthetic post-manufacture decoration and personalisation would seem to be desirable to the end-user.

- By adopting the feedback given in this study, undertaking trials conducted at a race-specific intensity of the athlete end-user may reduce the need to perform post-manufacture ad-hoc prostheses modifications.

Keywords: product attachment; prostheses; sport; cycling; disability

\section{Background}

\section{Athletes \& prosthetics technology}

Cycling with a disability competitively is formally termed 'paracycling'. Such athletes are categorised into one of four types of disability based upon the level of physical functionality they possess (http://www.uci.ch/para-cycling/about/). However, as competitive sport with a disability continues to evolve, so does the technology used to facilitate it. In the case of those possessing limb absence, this may require the use of prosthetics technology to help support their ability to perform the act of racing a bicycle. This technology may occur in the form of orthotic supports and customised methods of attachment and is typically bespoke in construction. Such technology has been investigated to ascertain if it can influence performance [1] or even be claimed as performance enhancing [2].

There are several models and frameworks which are recommended to support assistive technology development such as prosthetic limbs. Some of these examples include the VDI 2242 model [5 p.18], a modified 'Classification of Functioning, Disability and Health' framework [3] and the EMFASIS framework [4]. However, these models are aimed at the development of assistive technology in general and not the specific nuances that an athlete with a disability may or may not have. In addition, the 
consideration of any subjective or emotional requirements that may influence the prosthetics design generally only centre on that of prosthetic socket fit [5].

There has been a reported paucity of available case studies of sports prostheses design to help inform practitioners [6]. The limited case studies have included prostheses designs for swimming [7], running [8], athletics [9], golf, fishing, baseball and cycling [10] skiing [11], triathlon [12] and snowboarding [13]. In all of these case studies, the emphasis has been on the devices functionality or the quantifiable mechanical properties of the device. The only subjective factor in evidence has been the quality of fit of the prosthetic limbs socket to the stump or any sensations of athletebased fatigue. However, with other forms of sports equipment such as tennis balls [14] and footballs [15], athletes have been shown to exhibit emotionally led perceptions of them. In addition, the athletes' body-image has been proposed to be an integral part of a sportsperson with limb absence psyche and wellbeing [16]. Therefore, the contribution that the visual appearance of a prosthetic limb has could potentially also be seen of crucial importance to para-athletes.

An investigation revealed that the prosthetic limb could provide to be a barrier to those wishing to participate in sport [17] thereby stressing the importance of this type of technology's general design. The Bragaru study's results indicated frustrations or commentary from participants that seemed to focus on the functionality of the prosthetic limb despite the acknowledgement that aesthetic appearance would be relevant. Yet, the Bragaru et al. study [17] stated that most of their findings surrounding these concerns were provided by non-athletes. It then inferred that whilst seven athletes with limb absence were surveyed in the study, these were mainly those who competed in wheelchair-based sports and not those where the technology provided such a fundamental need for forward locomotion, such as with cycling or running. As a result, the studies to date have not fully considered the needs of athletes that may utilise different types and levels of assistive technology. Either way, to designate the nature of the disability as a means for categorising the types of athlete could seem to being out of step or context with current paras-sports. For example, at the Paralympic Games, athletes are actually classified on the basis of their sport and the level of their functionality [18], not by the type of disability they possess. As a result, all the studies to date could be seen as too generalised and only begin to address the understanding of 
the prosthesis/end user relationship. A more sports and context-specific approach may help enrich this area further.

\section{Technology and emotional attachment}

A prosthetic limb is ultimately a product whose aims are to satisfy its end users expectations. Whilst functionality and performance may well be inferred as a main driver of this satisfaction, it has also been suggested by consumer researchers that possessions or products have a role in maintaining a consumer's self-concept and sense of identity [19]. This ultimately leads to an end-user forming an attachment to a product. Product attachment is concerned with an emotive relationship the user may have to a specific object [20]. Ball and Tasaki [19] suggested that propositions or schemata relevant to the self may include objects of consumption. In such cases, objects of consumption could be considered synonymous with products and technologies such as a prosthetic limb. Ultimately then, such an object or product is then tied to an individual's self-worth [19]. This may be particularly pertinent with athletes since a social-cognitive approach [21] suggests that the public self is for social recognition and status, the private self seeks individual achievement up to some personal standard and the collective self seeks to attain the goals of a reference group. All of these would seem directly applicable to athletes and the sporting environment that they are immersed in.

The emotional attachment to a product is complex and influenced by its branding [22]. Likewise the attachment is proposed not to be of a static value and can change over time [23]. For example, it can rise from early to mature ownership and then begins to decline as the user begins to consider replacement or disposal [19]. However, prosthetic limbs are ultimately limb replacements and are restorical in their nature [23]. It is not known comprehensively how variable and intense the level of product attachment is to something that physically attaches to an athlete with limb absence (as a prosthetic limb does).

There is anecdotal evidence regarding the relationship between the user and a clinically prescribed prosthetic limb. These have included use of an osseo-integrated prosthesis [24]. In this case, some of the 13 participants produced an emotional response to the technology and considered it 'part of them' - despite being fully aware of its artificial nature. However, some others segregated the technology as a mere tool and 
thereby treated it as such. The emotions produced in such cases surrounded frustrations when it was not functioning correctly or providing happiness when it provided the ability to perform tasks which gave them pleasure. Likewise, prosthetic limbs have also been indicated to positively or negatively influence their user's body image [25]. As a result, whilst the direct emotional relationship with sports technology has not been explored, the recognition of an emotional reaction to prosthetics technology by nonathletes suggests this is worthy of further investigation.

It is not known if competitive athletes utilising a prostheses would produce different or similar responses to non-athletes. However, it has been proposed that when compared to a generalised population, those possessing a disability do have a different or lower level of body-esteem than those who are able-bodied [16]. Likewise, there is evidence that elite athletes are different to the general population when considering their emotional or psychological responses in terms of their attitudes to body image too [26]. As a result, whilst this is not directly applicable to the scope of this paper, it could be seen that if both athletes and those possessing some level of physical disability differ from the general population, it is not unreasonable to assume that athletes with a disability would then also differ from able-bodied athletes too.

Product personalisation and customisation has also been suggested as being a catalyst to creating emotional attachment to products [27]. This observation is pertinent within the context of this paper since whilst sports prosthetic limbs can be generic in their design [8], these are bespoke items tailored to the needs of the individual in terms of their fit and performance [5]. It could be argued that any desire to colour or decorate their prosthetic limb in such a way is to denote their achievements, status or image and therefore could be seen as akin to the technique of tattooing. The practise of tattooing provides psychological reassurance and an increase in self-confidence to the recipient [28] whereas an increase in self-confidence has been shown to correlate strongly with sporting performance [29]. Such considerations could therefore potentially facilitate a placebo effect. As far as competitive sport is concerned, the use of placebos is well documented [30] although these typically centre on chemical, nutritional or scientific interventions and not those surrounding artefact-based technology. However, there has been an account that a new and unproven design of squash racket still allowed players to perform better due to a potential placebo effect [31]. A significant percentage of athletes have reported that they felt a placebo effect would influence their performance. This effect could be subconsciously utilised by athletes with a disability positively. 
Ultimately, product personalisation requires a degree of effort to be invested by its user, in the guise of self-expression and ultimately can lead to a level of emotional bonding [27]. As a result, product personalisation and self-expression may well have the potential to be seen of value with assistive technology such as prosthetic limbs.

To begin to explore the relationship an athlete with limb absence may or may not possess with their prosthetic limb, an investigation is undertaken to ascertain if this is the case in a relevant sample population. From this, a conceptual model is then created to serve as a recommendation to medical practitioners to aid sports-specific prosthetic limb design in the future.

\section{Method}

This research utilised a qualitative approach and sought to investigate the relationship that paracyclists have with their cycling-specific prosthetic limbs. To maximise participation, the cycling discipline itself included athletes who undertook road racing, time trialling, track cycling or a variations of these. Institutional ethical approval was obtained for this study and all participants gave informed consent prior to the study's implementation.

The participants were required to complete a structured open-ended questionnaire. The respondents were purposively selected based upon pre-defined inclusion criteria. The two inclusion criteria were:

- An athlete with limb absence who required the use of a prosthetic limb (be it upper or lower limb) when performing the act of cycling competitively.

- A cyclist who has competed to at least national championship level (and ideally international level in the form of Paralympic Games, World Championship or Invictus Games participation).

Initial contact was established using clinical prosthetists as gatekeepers. The survey was administered via electronic mail. None of the participants were aware of the identity of any of the other respondents taking part at any stage of the study. Once the survey was 
completed, follow-up contact was made for any responses that required clarification or when notable survey answers were felt worthy to be explored further.

The survey comprised 31 questions. The direct source of these questions were from three separate studies that explored product attachment in consumer behaviour [19] [20] [27] but had some of the terminology contained within them altered to make it specific to this study. These three previous studies all obtained satisfactory internal consistency when using Cronbach's Alpha. The questions were then changed from a closed-ended to an open-ended philosophy to enhance the volume and depth of information.

The main questions were grouped into seven sub-sections. These sections were organised with a strategy that it started with the least challenging and adverse questions which would then increase in perceived depth and reflection section-by-section. The structure and themes are summarised in table 1.

\section{[INSERT TABLE 1 HERE]}

The participant responses were then assessed using thematic analysis using an open coding process by the authors. This method is inherently qualitative in nature and utilised the descriptive approach as expressed by Aronson [32]. Any themes would be defined as consistent components or fragments of ideas or experiences [32]. Each participant's response was read separately but also together on a question-by-question basis to help enhance this coding process. This thematic analysis was then used to produce a framework derived from the participant's responses. Ultimately, the resulting framework would be proposed to provide guidance for the assistive technology development process.

\section{Results}

Five participants completed the survey. All five respondents were male, elite-level paracyclists. Four were cyclists who would compete on the road and within a velodrome environment and the remaining cyclist was a road cyclist whose main competitive interest was in triathlon.

The age of the respondents ranged in age from 31 to 55 years (Mean=39, $\mathrm{SD}=10$ ). 
The athletes had themselves either sought out private funding for their limbs or been rewarded by some means to reduce the normal cost of such limbs. It should be noted that any funding of the athletes limbs were outside and independent of this study. The current age of the athletes cycling prostheses was a mean average of 22 months $(\mathrm{SD}=14)$ and a range of 6 months to 3.5 years old. However, one prosthesis was particularly older than the others (whereas all of the others were 2 years old or less).

The transcripts and post survey contact revealed three key overarching recurrent themes from the five respondents. These three themes were

- Athletes possessed a knowledge of the factors that they feel positively influence their performance in their chosen sport (and those required by their prosthetic limb as a result).

- That practical changes and adjustment were made to their prosthesis and occurred as a result of their competitive experiences after the limb was initially manufactured and supplied.

- That there was little indication of any conscious emotional attachment of the athlete to the cycling-specific prosthetic limb that they use.

These three themes are clarified and expanded.

\section{Knowledge of performance factors}

All respondents detailed an awareness of what factors they felt were required for them to perform to their highest potential when using a cycling-specific prosthetic limb. The responses typically and frequently saw mention of aerodynamics (or using the abbreviation 'aero'). A range of these responses included:

"It's not very aero but I don't think [as an above-knee amputee] there is much else out there".

"After that, aerodynamic features are important. Anything to reduce drag can lead to faster times". 
Likewise there was mention of the prosthesis providing the ability to transfer their power into forward motion or the ability to use it or produce the physiologically derived power when in their riding position. For example:

"It [the prosthesis] helps me get into a more race orientated position that helps me go faster"

"Very basic testing of the cycling leg compared to a walking prosthetic shows a massive increase in power output for starters"

However, the more recurring aspect within this theme was surrounding their perceived comfort of using the limb. This could be either that their prosthesis was comfortable to use, was not comfortable to use or was unpleasant and actually a barrier to their sports participation. The responses did not specifically detail which aspects or components of their prosthesis made it more or less comfortable. A range of these responses included:

"Fit is the primary concern. A good fit means being able to train and race with less pain, and for longer”.

"[I need] something that enables me to walk and ride without pain".

"Sometimes they fit and feel great and other days they don't fit that well and are painful to wear".

\section{Experience-led prosthesis modification}

Several of the athletes mentioned that they personally had made changes to their prosthesis as a result of their training and competing experiences. Examples of this included:

"I have added a ferrier coupling for [prosthetic from the bike] quick release". "I did add a thin rubber bushing...... to enable lateral ankle motion" "I added 10mm to the forearm length. I felt that I was too stretched on the left hand side".

\section{Lack of product attachment}

The concept of product attachment was attempted to be identified using 19 specific questions in the survey that explored their relationship with their prosthesis and their 
reaction to several hypothetical scenarios. For example, the respondents were highly diverse in their opinion on whether they felt that their prosthesis indicated their athletic status. Some responded with a simple 'no' or a suggestion that they had 'no feelings at all' about the statement provided to them. However, two others felt it did but only from the perspective of those observing them. Conversely, none of the respondents felt that their prosthesis connected them to others within the sport. More importantly, there was a consistent theme that the prosthesis was merely there to act as a tool to perform the act of cycling. For example:

"My cycling prosthesis has a sole purpose: to enable me to ride my bike".

This practical, objective or dissociative stance was reinforced by several responses to questions asking the athletes about a hypothesised loss or damage to their prosthesis and their personal feelings should this situation occur.

"I'm happy I have it, but would trade it for a better model in a heartbeat". [upon the loss of the prosthesis] "Yes, as I will not be able to ride my bike and riding my bike is what I love doing".

[upon the destruction of the prosthesis] "Accidents happen. Presumably it wasn't malicious so I can't see why I'd feel like it was a personal attack'. "I could be super angry [before a race or an important event]. [However if there is] enough time to repair or build a new one, I don't mind".

Four of the five athletes consistently across the 19 questions provided no indication in their responses of any affiliation, self-expression, attachment or emotional significance to/of their prosthetic limb. Only one athlete of the five did demonstrate content that indicated a consistent theme of product attachment to their prosthetic limb. This case typically was manifested in that the limb itself reminded them of geographical locations or specific competitions that they had taken part at in the past as well as their concerns over its replacement. Their feedback covered aspects like:

"It reminds me when I saw the para-cycling events on the velodrome in the London 2012 games and I was inspired by that". 
[in could another prosthesis be as meaningful] "Most likely not ....... It will take some time to get used to something else".

In addition this athlete felt that the prosthetic limb supported their values, represented them visually as an athlete, provided a connection to both the sport and other athletes within it and fitted their overall identity. However, caution should be applied in this case as the same respondent also suggested that if someone was admiring their prosthesis, they would only feel pleased due to the process that they had undertaken to develop it and the time spent optimising it for its intended purpose. This pragmatic view was also supported that if their prosthesis was lost, they would feel the same with or without it and that whilst it was considered part of themselves when cycling, the fact this loss prevented them from cycling was actually the main concern.

\section{Discussion}

The relatively small number of respondents in this study could be perceived as being small and therefore the findings of this study must be considered limited. However, it should be noted that the number of respondents recruited in this study are indicative of those with this type of disability that compete within contemporary paracycling [33]. As a result, the sample in this study was judged to be reflective of this specific environment but further studies would be required across a wider range of sports to assess if similar psychosocial behaviour is evident with athletes with a disability in general.

The participants in this study all demonstrated a relatively detailed knowledge of what their prosthesis required in terms of its functionality and its subsequent impact on their performance. The recurring theme of comfort would seem obvious as the connection between user and prosthesis is so direct and is a typical concern with prostheses design in general [5] and those who wish to undertake sport with some form of disability [17]. Aspects such as the importance of aerodynamics are quite commonly discussed, so again, it was not unexpected to see it recorded here.

Several of the athletes referred to their need to modify their prosthesis when it had been used. These involved issues surrounding its fit or its comfort. It is possible that these issues could not or were not investigated sufficiently when the prosthesis was originally designed. As a result, this recurring theme would suggest that if it is 
experience when training or competing that highlights the need for such modifications, it should be ensured that the prosthesis is tested under those conditions at the point of its development. The considerations that the athletes raised in this study (such as prostheses-based comfort when in the racing riding position or how it is attached), could be addressed with tests and simulations of when the athlete is cycling under competitive conditions. For example, whilst some tests in the past have seen the functional fit tested by using static cycling trainers [1], this is not representative of competitive cycling. As a result, it is recommended that field trials should be incorporated at race pace and at the targeted physiological intensity to avoid these ad-hoc modifications later.

Previous studies have stated that an emotional attachment to products can exist [20]. However, this same trait was not supported extensively in this study. However, there may be several reasons why this would be the case. Initially, the respondents were (or had been) full time professional athletes. The ultimate need by an athlete is to perform within a competitive environment [34] and so it was mentioned that the limb would be discarded as soon as it was felt by the athlete that this could no longer be achieved or could be superseded by something more beneficial. For example, one of the respondents heavily focused on the technical performance of their prosthetic limb and provided multiple answers that stated that replacement of their limb for something 'better' was not an issue for them. These views have been echoed by athletes with limb absence in other studies before [17].

The sentiment of a prosthetic limb merely being a means to an end was reported in this study but has also been echoed before with other sports such as running [23]. In the Dyer et al. study, the running prosthesis were reported by its sports stakeholders to merely facilitate their participation and to restore the lost functionality to the athlete. However, several of the respondents mentioned here the need to maximise their prostheses performance. As a result, it seems that these cyclists may be more receptive or more aware of the potential mechanical ergogenic effect than the aforementioned runners were in that previous study.

Whilst four of the athletes did not provide responses that gave clear evidence of product attachment, it is feasible that this relationship could still exist but in an alternative subconscious or unconscious form that the questionnaires design was unable to provoke. One athlete had decorated their prosthetic limb themselves with some of their achievements. Their responses suggested that they were happy to do this since this aesthetic change did not affect the functional performance of their limb. Furthermore, in 
a post survey follow-up, another of the respondents said that they had considered the same (and had only not done so as they could not think of an appropriate design at the time of this study). There is photographic evidence that other athletes who utilise a prosthetic limb have also adopted this practise. In such cases, paracyclists such as Jody Cundy have indicated this by incorporating their home nation's flag plus his status as a world champion whereas Craig Preece recoloured his with his favourite colour. This desire suggests an 'appearance follows performance' design philosophy that they felt added some personal value to them. This design philosophy is not unlike the similar 'form follows function' mantra coined by architect Louis Sullivan [35]. This philosophy proposed that with the process of design, that any functional needs should take priority over any aesthetic desires. It could be argued that an athlete's desires to colour or decorate their prosthesis in this way denoted their achievements, status or image and therefore reinforced the behaviour and existence of self-decoration described in this papers background section. This compliments observations seen from those who participate in competitive sport with a disability [16] and concerns over how they are perceived by others [17]. However, it is not clear in these studies if the prosthesis is seen as an extension of their physical form or merely an independent entity or artefact that is separate to it. In Dyer et al. [23], it was found that an expert panel did consider a running prostheses as a form of equipment and not as an extension of the human form. However, whilst the expert panel included a small number of elite athletes with a disability, their view in this consensus study would have been diluted by its nondisabled members. Whether this view would be shared by an elite athlete with a group made up entirely of athletes possessing limb absence would require further investigation. Ultimately, whilst self-decoration may appear to be a seemingly superficial or a trivial decision, this may be worth formal consideration at the prosthetic design phase as the basis for athletic performance enhancement. Any preference of imagery or colour on sports assistive technology (and its subsequent impact on performance) are worthy of future study.

The limitations of this study are that the survey interview pool, whilst representative of the sport, was still small. Likewise, the aims of this study required a conscious response from the athlete but does not account for any unconscious or subconscious relationships that the athlete could have with their assistive technology. An alternative non-invasive or covert method of survey such as an ethnographic approach could yield a broader understanding of the relationship between an athlete with limb 
absence and their prosthetics technology. In addition, each respondents recent and individual sporting results could influence their attitudes in this study. The timing of this study was intentionally placed to be performed early in the 4 year cycle before the next Paralympic Games took place. This decision was made to reduce any negative perceptions of their current prosthesis against their likely preferred competitive peak. However, it is not known how crucial the timing of this study would be to an athlete's perceptions on something that they stated in their responses "was a device that was essential to their performance'.

Finally, the key themes that resulted in this study provide some foundation to a proposed four-point 'framework of needs' for practitioners who design sports-specific prosthetics. This framework is proposed as:

a) The identification of the factors that influence performance in the athletes chosen sport.

b) To consider an 'appearance follows performance' approach.

c) To conduct sports specific trials of the prosthetic limb and conducted at a race specific intensity.

d) To identify any need for prostheses decorative personalisation.

This framework could provide additional considerations to a practitioner required to develop assistive technology for a competitive athlete with a disability.

\section{Conclusion}

Five athletes were surveyed to ascertain whether they possessed a relationship beyond merely that of a physical attachment with their prosthetic limb. Unlike conventional consumer products and their respective end users, four of the five athletes did not provide any unequivocal evidence to support the concept of a conscious non-physical attachment to their prosthesis. However, one athlete did provide some evidence of an emotional relationship with their prosthetic limb and two other respondents had incorporated some form of decorative personalisation or customisation. 
A thematic analysis led to a proposed framework of guidance for sports prosthetic limb development. A thematic analysis led to four consistent recurring themes being identified from the sample group responses and this resulted in the proposal of a framework to help inform the development of sports prosthetic limbs used in competitive sport. This framework should provide some guidance to practitioners and manufacturers in the creation of such devices in the future.

\section{Word count: 5797}

\section{Declaration of interest}

The authors report no conflicts of interest

\section{Acknowledgements}

The authors wish to thank the athletes who donated significant amounts of their time for this study.

\section{References}

[1] Dyer B. 'Scribble, sketch, carve, wrench and spin': a case study of a Paralympian's cycling prostheses design. In: UK High Performance Conference for Paralympic Sport Science and Sport Medicine 21-22 May 2013 Burton Upon Trent, United Kingdom. [2] Dyer B. The controversy of sports technology: a systematic review. SpringerPlus. 2015;4(1):doi.org/10.1186/s40064-015-1331-x

[3] Cowan R, Fregly B, Boninger M, Chan L, Rodgers M, Reinkensmeyer D. Recent trends in assistive technology for mobility. Journal of Neuroengineering and Rehabilitation. 2012;9(1):1.

[4] Plos O, Buisine S, Aoussat A, Mantelet F, Dumas C. A universalist strategy for the design of assistive technology. International Journal of Industrial Ergonomics. 2012;42(6):533-541. 
[5] Legro M, Reiber G, del Aguila M, Ajax M. Issues of importance reported by persons with lower limb amputations and protheses. Journal of Rehabilitation Research and Development. 1999;36(3):155.

[6] Deans S, Burns D, McGarry A, Murray K, Mutrie N. Motivations and barriers to prosthesis users participation in physical activity, exercise and sport: a review of the literature. Prosthetics and Orthotics International. 2012;36(3):260-269.

[7] Dyer B, Deans S. Swimming with limb absence: a systematic review. Journal of Rehabilitation and Assistive Technologies Engineering. 2017;4:1-10.

[8] Nolan L. Carbon fibre prostheses and running in amputees: a review. Foot and Ankle Surgery. 2008;14(3):125-129.

[9] Tingleff H, Jensen L. Case report: a newly developed socket design for a knee disarticulation amputee who is an active athlete. Prosthetics and Orthotics International. 2002;26(1):72-75.

[10] Bragaru M, Dekker R, Geertzen J. Sport prostheses and prosthetic adaptations for the upper and lower limb amputees: an overview of peer reviewed literature. Prosthetics and Orthotics International. 2012;36(3):290-296.

[11] McQuarrie K, Atterås K, McGarry A. Design of prosthetic components for skiing: a preliminary study. Journal of Prosthetics and Orthotics. 2015;27(4):154-160.

[12] Gailey R, Harsch P. Introduction to triathlon for the lower limb amputee triathlete. Prosthetics and Orthotics International. 2009;33(3):242-255.

[13] Minnoye S, Plettenburg D. Design, fabrication, and preliminary results of a novel below-knee prosthesis for snowboarding: a case report. Prosthetics and Orthotics International. 2009;33(3):272-283.

[14] Steele C, Jones R, Leaney P. Improved tennis ball design: incorporating mechanical and psychological influences. Journal of Engineering Design. 2008;19(3):269-84.

[15] Thompsett B, Harland A, Roberts J. Investigating the relationship between physical properties of a football and player perceptions. Procedia engineering. 2016;147:519-25. [16] Galli N, Reel JJ, Henderson H, Detling N. An investigation of body image in athletes with physical disabilities. Journal of Clinical Sport Psychology. 2016;10(1):1-8. [17] Bragaru M, Van Wilgen CP, Geertzen JH, Ruijs SG, Dijkstra PU, Dekker R. Barriers and facilitators of participation in sports: a qualitative study on Dutch individuals with lower limb amputation. PLoS One. 2013;8(3):e59881. 
[18] Tweedy SM, Vanlandewijck YC. International Paralympic Committee position stand-background and scientific principles of classification in Paralympic sport. British journal of sports medicine. 2011;45(4):259-69.

[19] Ball A, Tasaki L. The role and measurement of attachment in consumer behaviour. Journal of Consumer Psychology. 1992;1(2):155-172.

[20] Mugge R, Schifferstein H, Schoormans J. A longitudinal study of product attachment and its determinants. ACR European Advances. 2005;7:641-647

[21] Greenwald A. A social-cognitive account of the self's development. Self, ego, and identity. Integrative approaches. 1988;30-42.

[22] Malär L, Krohmer H, Hoyer W, Nyffenegger B. Emotional brand attachment and brand personality: the relative importance of the actual and the ideal self. Journal of Marketing. 2011;75(4):35-52.

[23] Dyer B, Noroozi S, Sewell P, Redwood S. The fair use of lower-limb running prostheses: a delphi study. Adapted Physical Activity Quarterly. 2011;28(1):16-26. [24] Lundberg M, Hagberg K, Bullington J. My prosthesis as a part of me: a qualitative analysis of living with an osseointegrated prosthetic limb. Prosthetics and Orthotics International. 2011;35(2): 207-214.

[25] Murray C, Fox J. Body image and prosthesis satisfaction in the lower limb amputee. Disability and Rehabilitation. 2002;24(17):925-931.

[26] Sundgot-Borgen J, Torstveit M. Prevalence of eating disorders in elite athletes is higher than in the general population. Clinical Journal of Sport Medicine. 2004;14(1):25-32.

[27] Mugge R, Schoormans J, Schifferstein H. Emotional bonding with personalised products. Journal of Engineering Design. 2009;20(5):467-476.

[28] Kosut M. Tattoo narratives: the intersection of the body, self-identity and society. Visual Studies. 2000;15(1):79-100.

[29] Woodman T, Hardy L. The relative impact of cognitive anxiety and selfconfidence upon sport performance: a meta-analysis. Journal of Sports Sciences. 2003;21(6):443-457.

[30] Bérdi M, Köteles F, Szabó A, Bárdos G. Placebo effects in sport and exercise: a meta-analysis. European Journal of Mental Health. 2011;6(2):196-212.

[31] Beedie C. Placebo effects in competitive sport: qualitative data. Journal of Sports Science \& Medicine. 2007;6(1):21. 
[32] Aronson, J., 1995. A pragmatic view of thematic analysis. The qualitative report, 2(1):1-3.

[33] Dyer B. Cycling with an amputation: a systematic review. Prosthetics and Orthotics International. 2016;40(5):538-544.

[34] Dyer B, Woolley H. Development of a high-performance transtibial cyclingspecific prosthesis for the London 2012 Paralympic Games. Prosthetics and Orthotics International. 2017:doi: 0309364616682386.

[35] Russell B, Motlagh D, Ashley W. Form follows function: how muscle shape is regulated by work. Journal of Applied Physiology. 2000;88:1127-1132. 